\title{
Identification of the influence of the heating upon the heat transfer during pyrolysis process used for End-of-Life tires treatment
}

\author{
Ivanka Zheleva ${ }^{1,{ }^{*}}$, Ivan Georgiev ${ }^{2}$, and Margaritka Filipova ${ }^{1}$ \\ ${ }^{1}$ Department Thermoingeneering, Hydraulics, Ecology, Ruse University, 7017, Ruse, 8 Studentska \\ Str., BULGARIA \\ ${ }^{2}$ Department Applied Mathematics and Statistics, Ruse University, 7017, Ruse, 8 Studentska Str., \\ BULGARIA
}

\begin{abstract}
End-of-Life tires (EOLT) are waste that does not practically decompose in nature and because of this their sound treatment is needed for environment protection. One of the possible methods for such a treatment is pyrolysis process. Globally, around $23 \%$ of all EOLT are processed through pyrolysis, whereas in the Republic of Bulgaria only 5\% are processed by pyrolysis. This shows that for Bulgaria this method pyrolysis still has a good potential for development and further research. In our previous paper [1], an adequate mathematical model of non-stationary heat transfer during pyrolysis used for the treatment of end-of-life tires has been developed. A numerical algorithm has been also developed in MATLAB to solve the respective mathematical initial and boundary value problems. In this study on the base of the previously developed model we examine the temperature regimes in the pyrolysis station with three cameras and their strong dependence upon the characteristics of the initial heating. Results for the temperature fields, temperature isolines and gradients for different kind of initial heating of the process are presented and commented.
\end{abstract}

\section{Introduction}

End-of-Life tires (EOLT) are waste that practically does not decompose in nature and because of this their sound treatment is needed for environment protection. One of the possible methods for such a treatment is pyrolysis process. Thus pyrolysis is an opportunity to solve the ecological problems related to the accumulation of large quantities of end-oflife tires. Pyrolysis is a chemical process that takes place without the presence of oxygen. Pyrolysis differs from the combustion process due to the lack of waste products. Globally, around $23 \%$ of all EOLT are processed through pyrolysis, whereas in the Republic of Bulgaria this percentage is much smaller - only 5\%. This shows that for Bulgaria this method still has a good potential for development and further research. In Republic of Bulgaria there are several pyrolysis stations working for treatment of end-of-life tires but their management is predominantly manual and therefore not efficient. Because of this the

\footnotetext{
*Corresponding author: izheleva@uni-ruse.bg
} 
theoretical examination of the temperature regimes in that kind of stations is needed. In our previous paper an adequate mathematical model of non-stationary heat transfer during pyrolysis used for the treatment of end-of-life tires has been developed. A numerical algorithm has been also developed in MATLAB to solve the respective mathematical initial and boundary value problems [1].

In this study we examine the temperature regimes in the pyrolysis station with three cameras and their strong dependence upon the characteristics of the initial heating. Results for the temperature fields, temperature isolines and gradients for different kind of initial heating of the process are presented and commented.

\section{Mathematical posing of the problem}

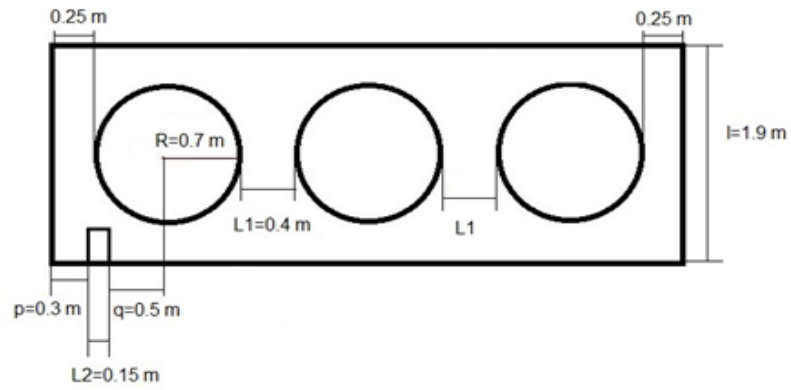

Fig. 1. Horizontal cross section of the pyrolysis station with three cameras and one heater

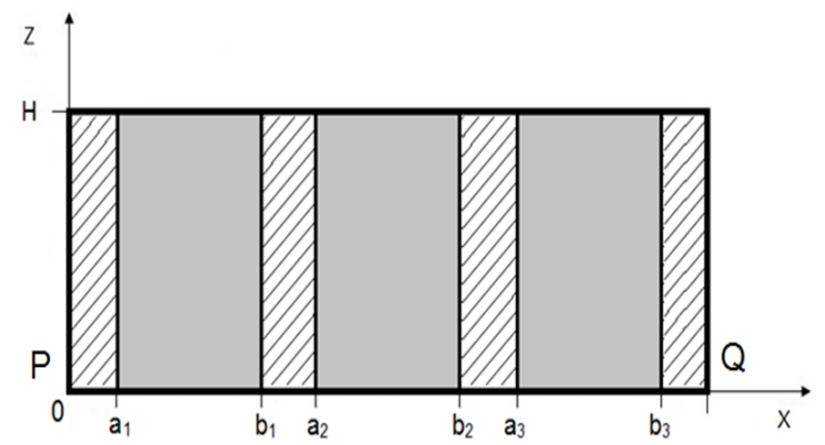

Fig. 2. Vertical cross section of the pyrolysis station with three cameras in the plane Oxz, $a_{1} b_{1}, a_{2} b_{2}$, $\mathrm{a}_{3} \mathrm{~b}_{3}$ - diameters of pyrolysis cameras, $1.4 \mathrm{~m}, \mathrm{OH}-1.45 \mathrm{~m}, \mathrm{PQ}=5.5 \mathrm{~m}$

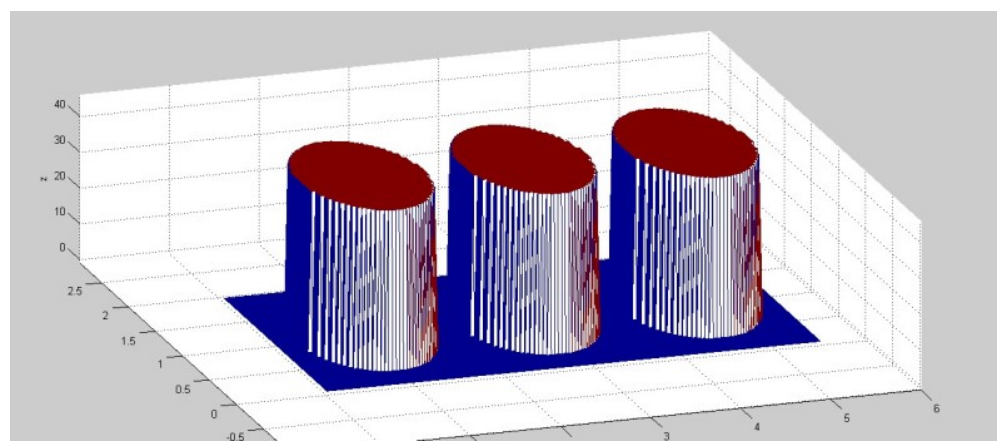

Fig. 3. 3D figure of the pyrolysis station with three cameras 


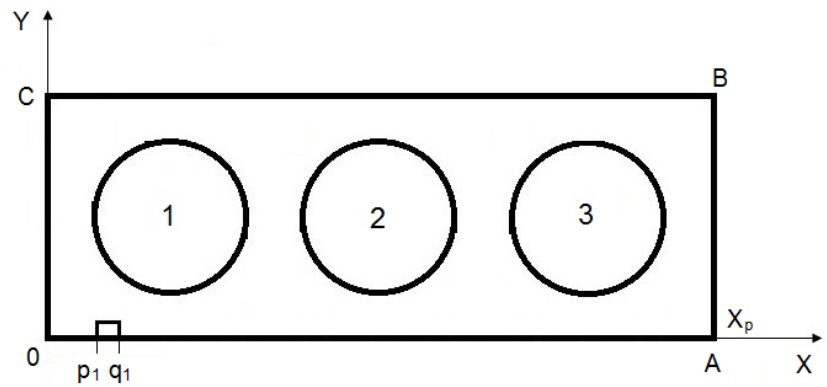

Fig. 4. Geometrical area for the first model in the plane Oxy, $\mathrm{p}_{1} \mathrm{q}_{1}$ - burner, $\mathrm{p}_{1}=0.3 \mathrm{~m}, \mathrm{q}_{1}=0,45 \mathrm{~m}, 1,2,3$ - circles - bottoms of pyrolysis cameras, $\mathrm{OA}=5,5 \mathrm{~m}, \mathrm{OC}=1,9 \mathrm{~m}$, diameters of circles $-1,4 \mathrm{~m}$

Here, following [1] we will write the mathematical model for studying non-stationary heat transfer in pyrolysis chemical reactor (station) with three cameras and one heating burner, which are schematically presented in Fig. 1 - Fig.4. So the model for Oxy cross section (Fig.4) consists of the equation

$$
\frac{\partial T}{\partial t}=k\left(\frac{\partial^{2} T}{\partial x^{2}}+\frac{\partial^{2} T}{\partial y^{2}}\right)
$$

Here $\mathrm{T}$ is the temperature in Kelvin $\mathrm{T}[\mathrm{K}]$, and $\mathrm{k}$ is the coefficient of thermal conductivity, $[\mathrm{k}]=\mathrm{W} /(\mathrm{m} . \mathrm{K})$.

This equation has to be solved in the double-bonded geometric area of Fig. 4 under the following initial and boundary conditions:

$$
\begin{array}{ll}
\text { At } t=t_{0} T=T_{0}=20{ }^{\circ} C \text { for } \forall x, y & \\
\text { For } y=0, \forall t x \in\left(0, p_{1}\right) \cup\left(q_{1}, X_{p}\right) & \frac{\partial T}{\partial y}=k_{1}\left(T-T_{0}\right) \\
\text { For } y=H \quad \forall t, \forall x . & \frac{\partial T}{\partial y}=k_{1}\left(T-T_{0}\right) \\
\text { For } x=0 \forall t, \forall y . & \frac{\partial T}{\partial x}=k_{1}\left(T-T_{0}\right) \\
\text { For } x=L \forall t, \forall y . & \frac{\partial T}{\partial x}=k_{1}\left(T-T_{0}\right) \\
\text { For } y=0, \forall t x \in\left(p_{1}, q_{1}\right) & \mathrm{T}=\mathrm{T}^{*}(\mathrm{t}, \mathrm{x}) \text { from Fig. 5 }
\end{array}
$$

The thermal conductivity coefficients are respectively for refractory bricks $k_{I}=0,29 \mathrm{~W} /$ $m K$, for steel (material of pyrolysis chamber, circles 1, 2, 3 Fig. 1) $k_{2}=45 \mathrm{~W} / \mathrm{mK}$,

The model for Oxz cross section (Fig.2) consists of the equation:

$$
\frac{\partial T}{\partial t}=k\left(\frac{\partial^{2} T}{\partial x^{2}}+\frac{\partial^{2} T}{\partial z^{2}}\right) .
$$

This equation has to be solved in the geometrical area, shown in Fig. 2 with the following initial and boundary conditions 


$$
\begin{aligned}
& \text { At } t=0, T=T_{0}=20{ }^{\circ} \mathrm{C}=293 \mathrm{~K} \\
& \text { At } z=0 \quad \text { and } \quad x \in[0, Q] \\
& T=T_{01}(t) \\
& \text { At } z=H \quad \text { and } \quad x \in[0, Q] \\
& \frac{\partial T}{\partial z}=k_{*}\left(T-T_{0}\right) \\
& \text { At } \mathrm{x}=0 \text { and } \mathrm{x}=\mathrm{Q} \text { and } z=0 \text { and } z=H \quad \frac{\partial T}{\partial x}=k_{1}\left(T-T_{0}\right)
\end{aligned}
$$

Coefficient $\mathrm{k} *$ is equal to $\mathrm{k}_{1}$ if $x \in\left[0, a_{1}\right] \cup\left[b_{1}, a_{2}\right] \cup\left[b_{2}, a_{3}\right] \cup\left[b_{3}, Q\right]$ and $\mathrm{k} *$ is equal to $\mathrm{k}_{3}$ if $x \in\left[a_{1}, b_{1}\right] \cup\left[a_{2}, b_{2}\right] \cup\left[a_{3}, b_{3}\right]$ The function $T_{01}(t)$ is calculated after the first stage of modeling. Here $k_{3}=0,16 \mathrm{~W} / \mathrm{mK}$ is for the material of the tires.

From the mathematical point of view the problem is to fine the temperature $T$ as a function of space and time $T(t, x, y, z)$ in the geometrical area, shown at Fig.1 - Fig.4, by solving the initial and boundary value problems for equation (1) and (8) with initial and boundary conditions respectively (2) - (7) and (9) - (14). To find solutions of these problems is very complicated because the geometrical areas are very complex (it is not a convex polytope) and also the coefficients of thermal conductivity are different in the different subareas of the geometric area.

To solve these mathematical problems we will use the numerical algorithm, developed by using MATLAB software and proposed in our paper [1].

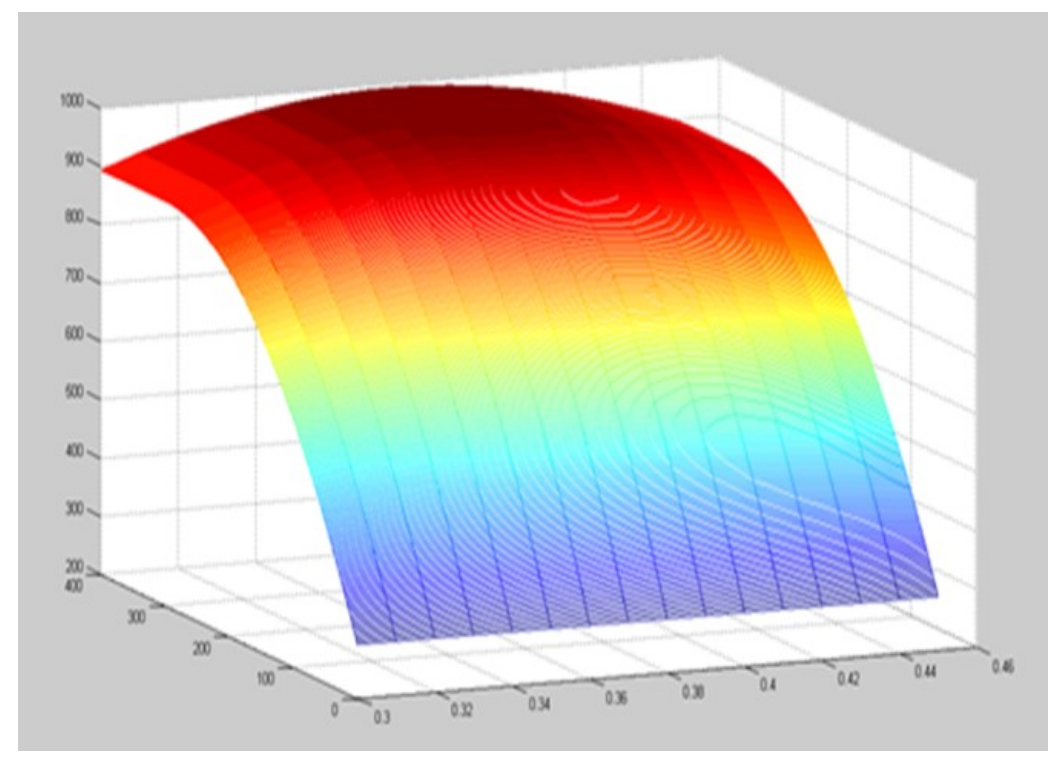

Fig. 5. 3D Graphic of the temperature $T^{*}(t, x)$ of the burner as a function of the space $0.3 m<x<0.45 m$ and time and $T_{\max }=900 \mathrm{~K}$. 


\section{Modelling of the heating process}

The heating of the pyrolysis stations is carried out by one burner placed on the bottom of the station (see $\mathrm{p}_{1} \mathrm{q}_{1}$ on the fig.3). The used fuel can be different. To describe the heating process of the pyrolysis station we will create a function $T^{*}(t, x)$ for $p_{I} \leq x \leq q_{1}$ and for $\forall t$. We suppose that $T^{*}(t, x)$ is symmetric quadratic function with $T_{\max }$ in the middle of the interval for $p_{1} \leq x \leq q_{1}$ and for $\forall t$

Using also MATLAB software we develop $T^{*}(t, x)$. The Fig. 5 shows such a function for $p_{I}=0.3 \mathrm{~m}, q_{I}=0.45 \mathrm{~m}$ and $T_{\max }=900 \mathrm{~K}$.

In this paper we study the influence of the heating on the whole pyrolysis process. We look at two heating regimes - with $T_{\max }=2773 \mathrm{~K}$ and $T_{\max }=32730 \mathrm{~K}$.

\section{Results and Discussion}

First we examine the heating regime with $T_{\max }=2773 \mathrm{~K}$. Figures 4,5 and 6 show the calculated temperatures in Oxy plane at $\mathrm{t}=500 \mathrm{~s}, \mathrm{t}=3600 \mathrm{~s}$ and $\mathrm{t}=15000 \mathrm{~s}$. Figures 7,8 and 9 show the temperatures in Oxz plane at the same moments of time $t=500 \mathrm{~s}, \mathrm{t}=3600$ $\mathrm{s}$ and $\mathrm{t}=15000 \mathrm{~s}$. Figure 10 shows the temperature as a function of time (at $\mathrm{t}=500 \mathrm{~s}, \mathrm{t}=$ $3600 \mathrm{~s}, \mathrm{t}=15000 \mathrm{~s}$ ) in the Oxy plane in the PQ section, which is the initial and boundary condition of the mathematical problem of studying the heat exchange of the pyrolysis process in the Oxz plane.

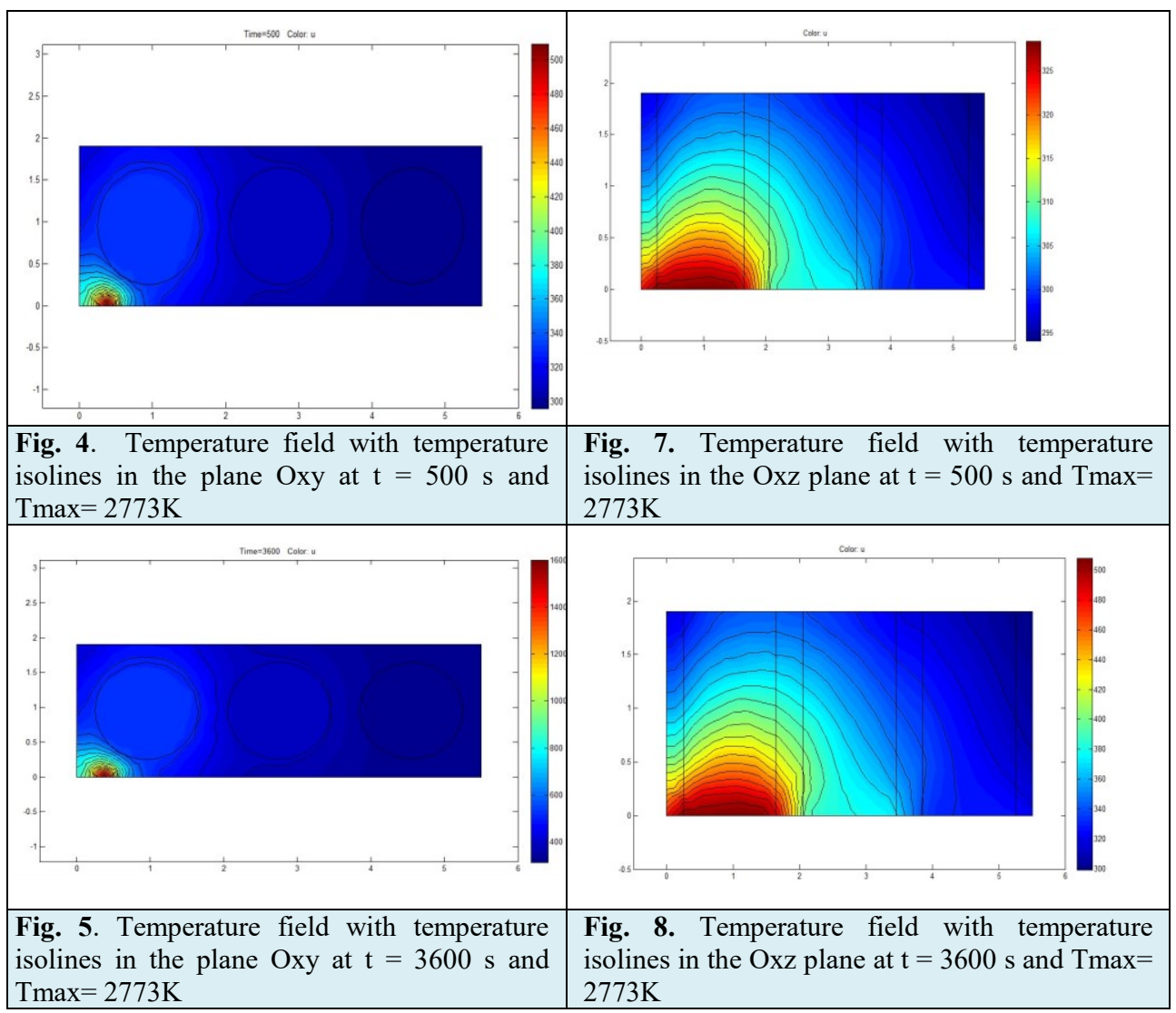




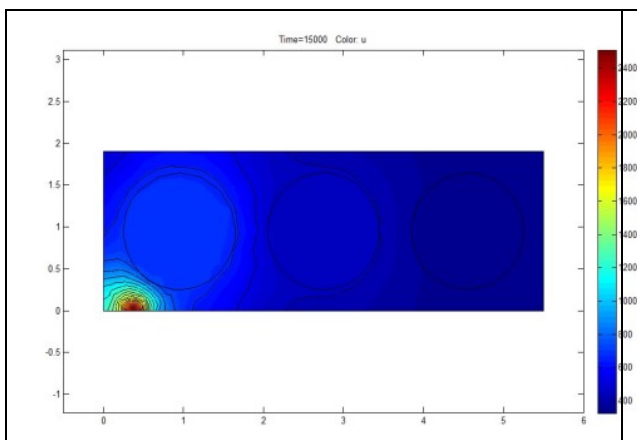

Fig. 6. Temperature field with temperature isolines in the plane Oxy at $\mathrm{t}=15000 \mathrm{~s}$ and Tmax $=2773 \mathrm{~K}$

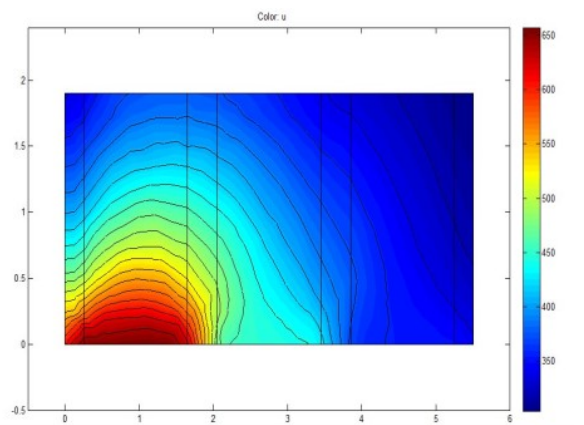

Fig. 9. Temperature field with temperature isolines in the Oxz plane at $\mathrm{t}=15000 \mathrm{~s}$ and Tmax $=2773 \mathrm{~K}$

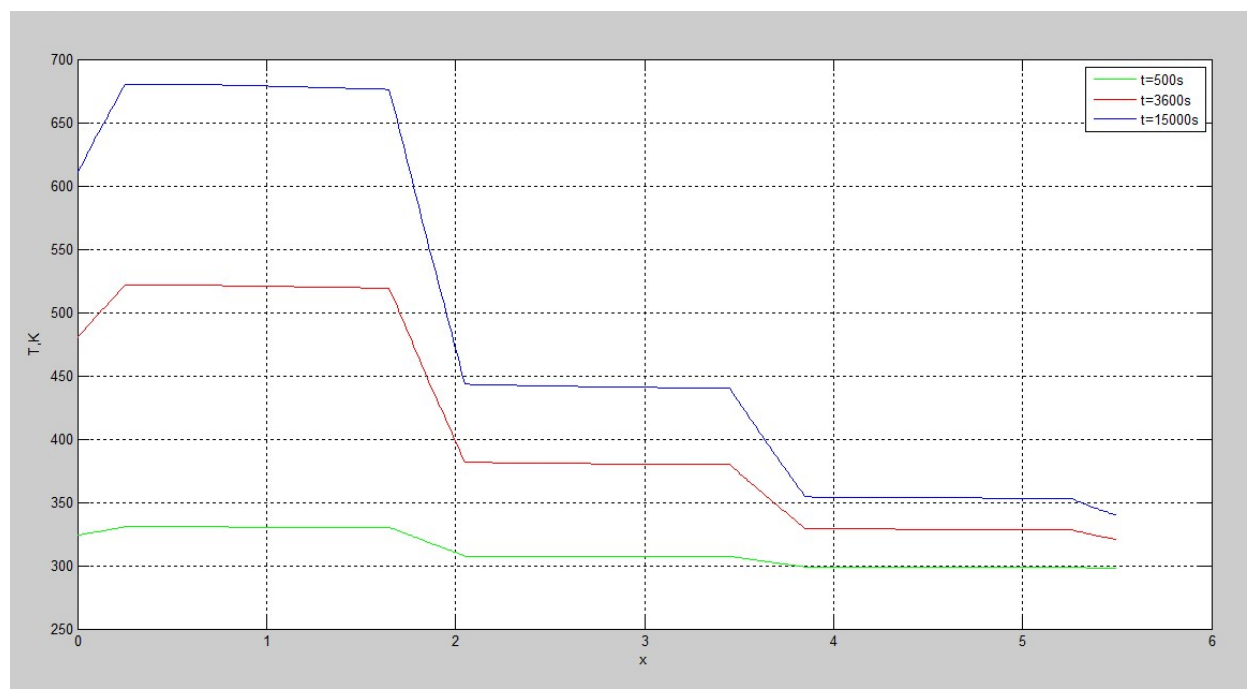

Fig. 10. Graph of the temperature as a function of time $T^{*}(t, x)($ at $t=500 s, t=3600 s, t=15000 s)$ in the Oxy plane in the PQ section, which is the initial and boundary condition of the mathematical problem of studying the heat exchange of the pyrolysis process in the Oxz plane

Second we examine the heating regime with $T_{\max }=3273 \mathrm{~K}$. Figures 11,12 and 13 show the calculated temperatures in Oxy plane at $\mathrm{t}=500 \mathrm{~s}, \mathrm{t}=3600 \mathrm{~s}$ and $\mathrm{t}=15000 \mathrm{~s}$. Figures 14, 15 and 16 show the temperatures in Oxz plane at the same moments of time $\mathrm{t}=500 \mathrm{~s}, \mathrm{t}=$ $3600 \mathrm{~s}$ and $\mathrm{t}=15000 \mathrm{~s}$. Figure 17 shows the temperature as a function of time (at $\mathrm{t}=500 \mathrm{~s}$, $\mathrm{t}=3600 \mathrm{~s}, \mathrm{t}=15000 \mathrm{~s}$ ) in the Oxy plane in the PQ section, which is the initial and boundary condition of the mathematical problem of studying the heat exchange of the pyrolysis process in the Oxz plane. 


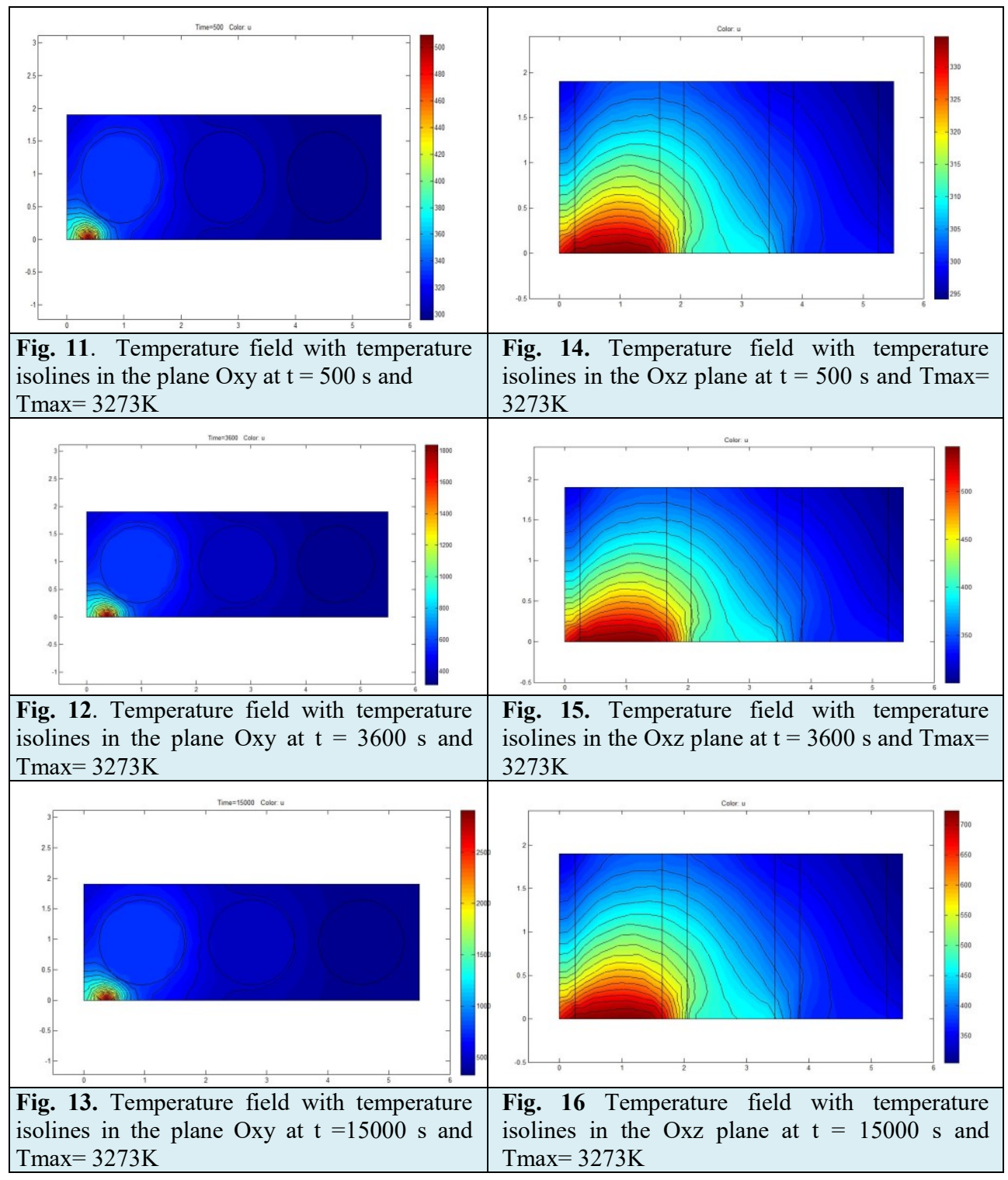

Figure 17 shows the temperature as a function of time (at $t=300 \mathrm{~s}, \mathrm{t}=3600 \mathrm{~s}, \mathrm{t}=$ $15000 \mathrm{~s}$ ) in the Oxy plane in the PQ section, which is the initial and boundary condition of the mathematical problem of studying the heat exchange of the pyrolysis process in the Oxz plane if $\operatorname{Tmax}=3273 \mathrm{~K}$.

If we compare the maximal temperatures at the bottom of the most heated camera (the left one) from Fig. 10 and Fig. 17 for $t=15000 \mathrm{~s}$ one will see that in the first case $\mathrm{T}^{*}=680^{\circ} \mathrm{C}$ (Fig.10) while in the second case $\mathrm{T}^{*}=750^{\circ} \mathrm{C}$ (Fig.17). 


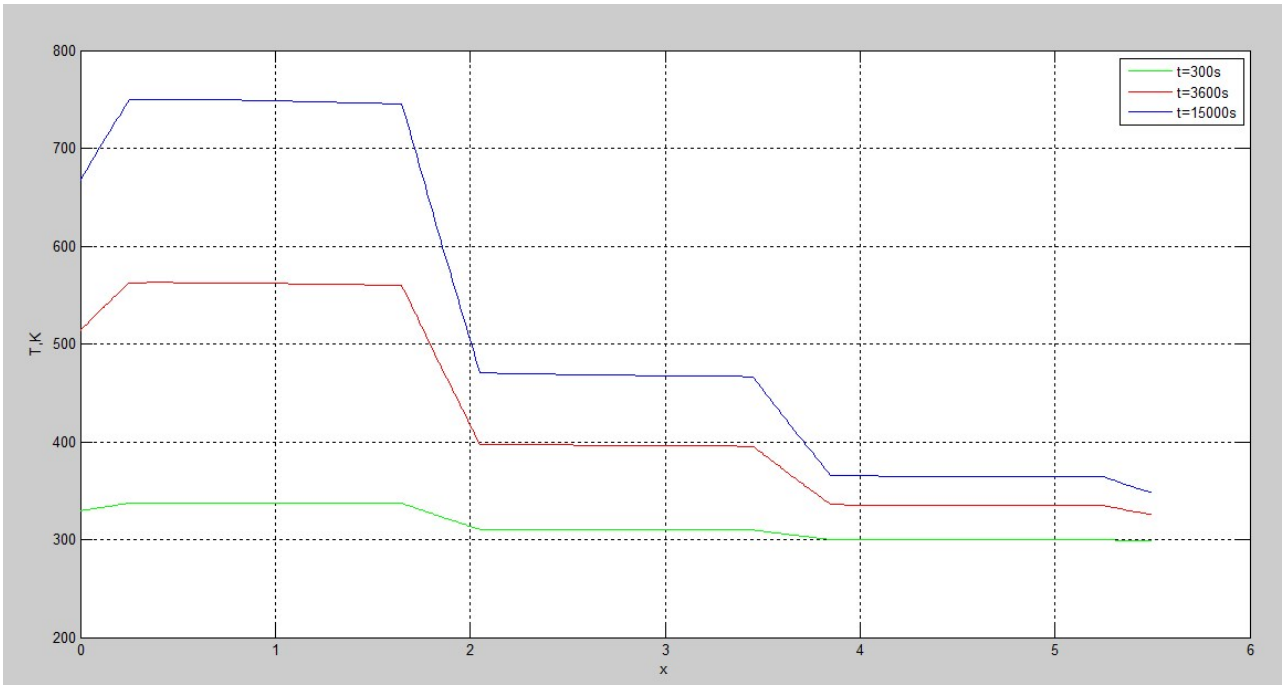

Fig. 17. Graph of the temperature as a function of time $T^{*}(t, x)($ at $t=500 s, t=3600 s, t=15000 s)$ in the Oxz plane in the PQ section, which is the initial and boundary condition of the mathematical problem of studying the heat exchange of the pyrolysis process in the Oxz plane

Figure 18 shows the temperature at $\mathrm{t}=15000 \mathrm{~s}$ on the upper end of the cameras $(\mathrm{z}=\mathrm{H})$ for the two heating regimes with $T_{\max }=2773 \mathrm{~K}$ - red line and with $T_{\max }=3273 \mathrm{~K}$ - blue line. The maximum temperature reached for $\mathrm{z}=\mathrm{H}$ in the first case is $\mathrm{T}=370^{\circ} \mathrm{C}$ and in the second case is $\mathrm{T}^{*}=388^{\circ} \mathrm{C}$.

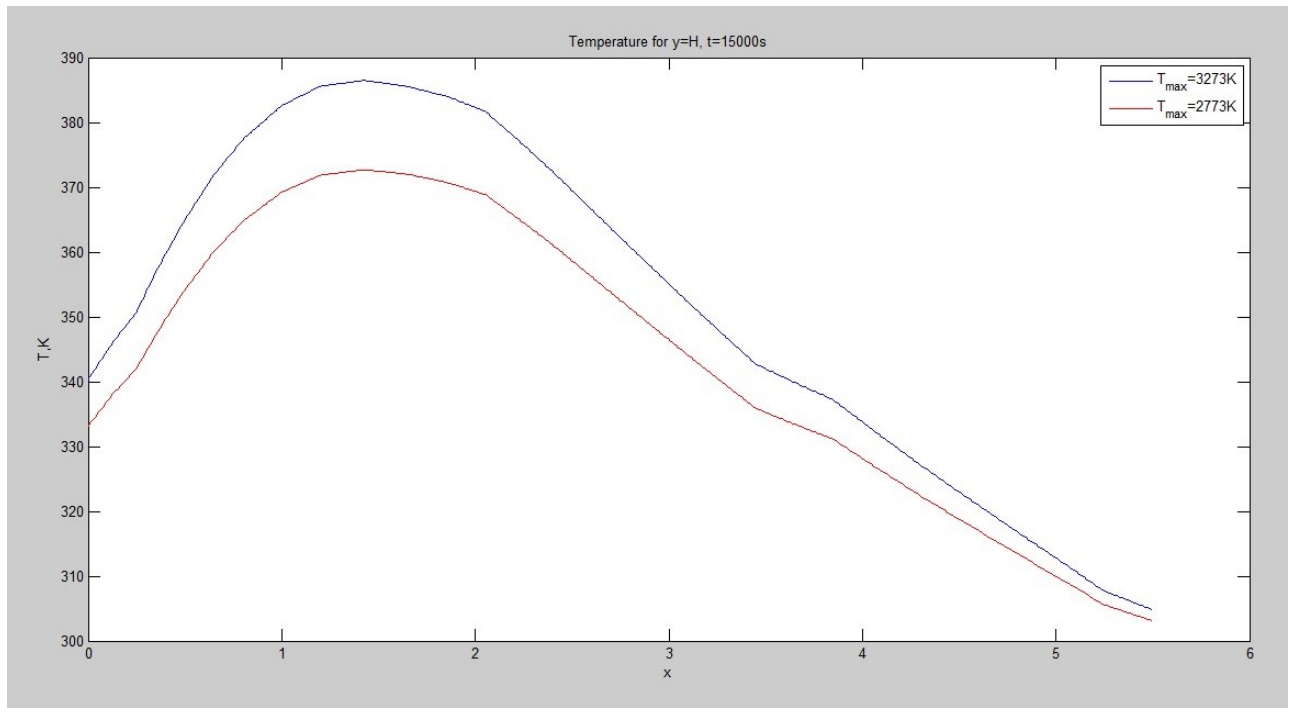

Fig. 18 Temperatures for $\mathrm{z}=\mathrm{H}, \mathrm{t}=15000 \mathrm{~s}$ for the two heating regimes with $T_{\max }=2773 \mathrm{~K}-$ red line and with $T_{\max }=3273 \mathrm{~K}$-blue line. 


\section{Conclusions}

An opportunity to solve the ecological problems related to the accumulation of large quantities of end-of-life tires is pyrolysis which is a complex process of thermal destruction. It is conducted usually in chemical reactors where the tires are heated to a certain temperature under which they are decomposed into several fractions - liquid, solid and gaseous. After the initial heating, the process is continued for a certain period of time, after which the reactor is allowed to cool. The liquid and solid products of pyrolysis are then removed and thus a pyrolysis cycle is completed. The gaseous fraction is a fuel mixture and usually is returned in the pyrolysis reactor for its heating. Within this technology a significant economic effect can be achieved because solid, liquid and gaseous substances received by pyrolysis are useful and the amount of the EOLT is reduced.

The management of pyrolysis stations for treatment of end-of-life tires in Republic of Bulgaria is predominantly manual and therefore not efficient. This necessitates the theoretical examination of the temperature regimes in that kind of stations, which determines the topic of the present paper.

Using an adequate mathematical model and a numerical algorithm for studding nonstationary heat transfer during pyrolysis used for the treatment of end-of-life tires [1] we explore the heating of pyrolysis process. Two different heating ways were described and tested. First was with $T_{\max }=2773 \mathrm{~K}$ and second with $T_{\max }=3273 \mathrm{~K}$. Results for temperature fields were obtained and commented. They can be used to more accurately choice of the temperature measurement position in the existing pyrolysis station and thus to improve its management.

This paper contains results of the work on project No 2017 - AIF - 3 financed by „Scientific Research Fund" of Ruse University.

\section{References}

1. I. Zheleva, I. Georgiev, M. Filipova, D. Menseidov, Mathematical Modelling of the Heat Transfer during Pyrolysis Process Used for End-of-Life Tires Treatment, AMiTaNS AIP Conference Proceedings (2017) (in print). 